\title{
MOOREN ULCER IN A CORNEAL GRAFT*
}

BY

\begin{abstract}
A. J. BOASE
Uganda

THE sequence of events in the following case make it one of unusual interest and warrant its being put on record.
\end{abstract}

\section{Case Report}

A male native of the Congo, about 35 years old, was brought to Mulago Hospital, Uganda, in February, 1954. He had become blind some months before from what seemed to be the very common condition of total leucoma adherens following a purulent ophthalmia. Each cornea was opaque and in neither eye could iris tissue be made out with the slit-lamp. Finger tension was normal, and there was vague perception of light. The case was considered hopeless, but as the patient had come a great distance and pleaded for something to be done, a $10-\mathrm{mm}$. penetrating keratoplasty was done on the left eye on February 25. To my great surprise the iris was found to be normal in all respects. A very small pyramidal cataract, presumably congenital, was seen in the centre of the pupillary area. The graft was fixed with edge-to-edge sutures. On March 8 it was beautifully clear, the iris pattern and the polar cataract were easily seen, and the illiterate patient readily identified small objects held at the end of his bed. He was very pleased with himself and impatient for the second eye to be treated.

On the following day the sutures were removed under pentothal, and it was then noted that a small peripheral zone at 5 o'clock was slightly hazy. Within a week the graft was bluish-opaque, and vision reduced to barely hand movements. Vascularization soon followed despite the local and systemic use of cortisone.

The outcome was of course not entirely unexpected, having regard to the total opacity of the host cornea, but the healthy state of the inner eye encouraged a slight hope of success with a re-graft. Because of the large size of the first graft $I$ had intended to reverse the usual procedure by using a smaller one. If this too became opaque one could always do a larger one at a later date. There was also the idea that whatever "antibody-antigen reaction" factor had induced opacity in the first graft might by that time have been neutralized, leaving the second to exert hypothetical therapeutic powers, perhaps to the extent of clearing the first.

These theoretical considerations came to nothing, for at the beginning of May, when the eye seemed to be ready for the second operation, the patient started to complain of pain, of which so far he had been remarkably free. Examination revealed a slight furrow at 5 o'clock equally disposed between graft and host. This rapidly spread in typical Mooren fashion and within 3 weeks had involved nearly all the circumference of the graft and most of the main area, leaving a small island connected to the periphery by a narrow bridge at 11 o'clock. The advancing edge was all the time deeply undermined and the eroded area showed the uneven "granular" appearance that a Mooren ulcer leaves in its wake. A paracentesis on May 27 was without benefit. The erosion went on until the 
entire superficial layers of the graft had disappeared. As far as I could tell the adjacent host rim suffered a like fate. At no time did it seem that perforation was likely to occur. The patient, now thoroughly despondent, refused further treatment and was taken away and lost sight of. The use of pentothal during the removal of the sutures proved to have been most unfortunate as he remained convinced that his eye was destroyed while he was asleep.

\section{Discussion}

Is it unreasonable to suggest that the original trouble may have been a bilateral Mooren ulcer? Admittedly, the corneal opacities were more dense than one expects to find in that condition, but one can hardly imagine a purulent ulcer involving the whole corneal surface without leading to perforation and a leucoma adherens, or at the least post-inflammatory damage to the iris. That such did not occur was clearly established in the case of the left eye, and there was no particular reason for choosing this eye rather than its fellow for the operation; they both presented a similar appearance. In favour of the Mooren aetiology was the patient's insistence, on close questioning after the event, that before he lost his sight pain was the main symptom. There does not appear to have been a frank purulent discharge, nor did the state of the tarsal conjunctivae suggest a recent severe inflammation.

In following the events in the graft, one is impressed by the new access of pain, which was really severe, at a time when it could no longer be ascribed to the reparative process of healing. Iritis as a factor might be discounted for the patient was on atropine and cortisone drops throughout. Is the pain to be explained solely by involvement of nerve-ends in the host rim of cornea, or can one deduce from it the complete integration of the graft with the host, even to the extent of a nerve supply? If so, is there any reason why the unknown factor that induces a Mooren ulcer should not influence this newly assimilated corneal tissue in precisely the same manner? For it would seem that the only obstacle to unlimited spread of a Mooren ulcer is lack of corneal surface: an assimilated graft should provide further territory for expansion. Dare one go further and suggest that the invasion of a graft by a Mooren ulcer could be accepted as evidence favourable to the concept that seeks to explain this syndrome on a neurogenic basis?

\section{Summary}

A case is described in which a corneal graft underwent the clinical syndrome of a Mooren ulcer. 